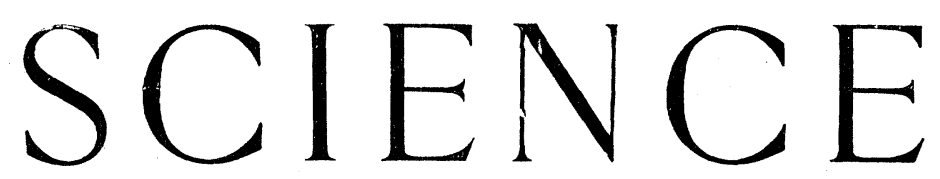

NEW YORK. FEBRUARY 24, 1893.

\section{THE ABSENCE OF AIR FROM THE MOON}

BY SIR ROBERT BALL, LOWNDEAN PROFESSOR AT CAMBRIDGE, ENGLAND.

Astronomers have long felt that the absence of air from the moon is a fact that demands some special explanation. Most of the globes in space which are known to us are encompassed by more or less copious atmospheres, why then is the moon an exception? why should there be a gaseous investment to the earth and to Venus, to Mars and to Jupiter, and why should the moon alone be devaid of such covering? The sun and other stars are also so very copiously endowed with gaseous surroundings that the total want of anything of the kind from the moon becomes all the more enigmatical.

At last a light has been thrown on the matter, and an explanation is now provided which is so consonant with the present state of physical knowledge, that I cannot hesitate to accept it. The absence of air from the moon is a necessary consequence of the kinetic theory of gases.

According to the principles of this theory, now generally accepted among physicists, any gas such as oxygen or hydrogen, is composed of molecules which move with an extreme degree of rapidity. The molecules of hydrogen, for instance, which are the most nimble of all the gases in their movements at ordinary temperatures, dash along so fast as to travel on the average somewhat more than 6,000 feet a second. Oxygen and nitrogen have movements which are generally much less than those of hydrogen. But it is to be noted that, in the course of their movements, individual molecules frequently attain velocities very much in excess of the average pace. This is the important point for our present purpose, for on it depends the explanation of the phenomenon of which we are in search.

It can be shown that the mass and the dimensions of the moon are such that if a body were projected upwards from its surface at a pace, let us say, of half a mile a second, that body would ascend to a very considerable elevation, ultimately, however, the attraction of the moon would overcome its outward movement, and the body would tumble back again. If, however, the initial pace were so much greater that it attained a certain critical amount of about a mile a second, then the missile, according to the laws of motion, would ascend from the surface of the moon and go on and on nerer to be again re-called by any power that the moon's attraction could put forth.

Let us suppose that the moon were now to be invested with a new atmosphere of oxygen or nitrogen. The molecules of these gases will, of course, be darting about with the velocities appropriate to their nature, but, generally speaking, the speeds with which they are animated remain within the limits of velocity which it is in the power of the moon to control. But these are only the average speeds, and it will frequently happen that individual molecules will be animated by a speed equalling or exceeding the critical pace of a mile a second; if this takes place at the upper layers of the moon's atmosphere, the little molecules will take leave of the moon altogether. Other particles follow in the same fashion, and thus it happens that an atmosphere composed of such gases as these we know could not permanently abide on the moon.

On the earth we have and we retain a copious atmosphere. The reason simply is that the earth is massive enough to require that a projectile shall attain a speed of about six miles a second before it goes off and takes leave of our globe. This velocity it would seem that the molecules of oxygen and nitrogen do not generally or ever reach. Hence it is that while the earth can retain the atmosphere with which it was endowed, the moon is unable to do likewise.

\section{SOME ERRORS IN THERMOMETER READINGS.}

BY FRANK WALDO, PRINCETON, N. J.

I HAVE understood that the long-awaited comparison of ordinary thermometers with the gas thermometer, at very low temperatures, has been carried out at the International Bureau of Weights and Measures at Sevres. However, I have been unable to get hold of any account of this work, as the official reports concerning it had not been received a short time ago even at the Weather Bureau Library. In Wild's Repertorium für Meteorologie, Vol. $\mathrm{XV}$., which has just been received, there is an account of some careful comparisons at low temperatures, which gives results probably not very different from those obtained at Sevres; and a little summary of this will undoubtedly be of interest to some readers. In the St. Petersburg paper, ${ }^{1}$ S. Hlasek gives a little summary of the condition of the thermometric standards of the Russian Meteorological Service from the time Director Wild took charge (about 1868) up to the present time. In the present communication, I will not trace through the various thermometer corrections as given by Hlasek, but will merely give the latest results, showing the corrections to be applied to the standard mercurial thermometer at moderate and low.temperatures and to the standard spirit thermometer at very low temperatures, to reduce them to the hydrogen gas thermometer, which is the inter national standard.

\begin{tabular}{|c|c|c|c|}
\hline \multicolumn{2}{|c|}{$\begin{array}{c}\text { Correction of the spirit thermometer } \\
\text { by Geissler. }\end{array}$} & \multicolumn{2}{|c|}{$\begin{array}{l}\text { Correction of the standard mercurial } \\
\text { thermometer, Geissler No. } 10 .\end{array}$} \\
\hline At & Correction. & At & Correction. \\
\hline$-5^{\circ} \mathrm{C}$ & $-0.56^{\circ} \mathrm{C}$ & $40^{\circ} \mathrm{C}$. & $-0.16^{\circ} \mathrm{C}$. \\
\hline-10 & -0.72 & 35 & -0.16 \\
\hline-15 & -0.90 & 30 & -0.16 \\
\hline-20 & -1.10 & 25 & -0.15 \\
\hline-25 & -1.36 & 20 & -013 \\
\hline-30 & -1.68 & 15 & -0.11 \\
\hline-35 & -1.95 & 10 & -008 \\
\hline-40 & -2.23 & 5 & -0.05 \\
\hline-45 & -2.47 & 0 & 0.00 \\
\hline-50 & -2.72 & -5 & +0.02 \\
\hline-55 & -2.95 & -10 & +0.07 \\
\hline-60 & -3.15 & -15 & +0.13 \\
\hline & & -20 & +0.22 \\
\hline \multicolumn{2}{|c|}{ A zero-point correction of $+0.39^{\circ} \mathrm{C}$. } & -25 & +0.27 \\
\hline \multirow{2}{*}{\multicolumn{2}{|c|}{$\begin{array}{l}\text { has been applied in assigning these } \\
\text { corrections. }\end{array}$}} & -30 & +0.25 \\
\hline & & -35 & +0.31 \\
\hline & & -40 & +0.36 \\
\hline
\end{tabular}

These corrections were obtained by means of a normal (Toluène) thermometer, Tonnelot No. 4932 , which had been compared with the hydrogen gas thermometer at Sevres.

1 Die Temperatur-scalen des Physikal. Cent. Observ. und lhr Verhältness zu der International Temperatur-scale, 1892. 
Since January, 1892, all of the thermometers verified at the Central Physical Observatory at St. Petersburg have been referred to the hydrogen gas thermometer at Sevres as a standard.

The thermometers verified between January, 18\%\%, and January, 1892, require the following (additional) corrections, in order to reduce their readings to this standard:-

$\begin{array}{ccc}\text { Temperature. } & \begin{array}{c}\text { Correction of the mer- } \\ \text { curial thermometers. }\end{array} & \begin{array}{c}\text { Correction of the spirtt } \\ \text { thermometers. }\end{array} \\ +40^{\circ} \mathrm{C} . & -0.16^{\circ} \mathrm{C} . & -0.2^{\circ} \mathrm{C} . \\ +35 & -0.16 & -0.2 \\ +30 & -0.15 & -0.2 \\ +25 & -0.14 & -0.1 \\ +20 & -0.12 & -0.1 \\ +15 & -0.09 & -0.1 \\ +10 & -0.07 & -0.1 \\ +5 & -0.04 & 0.0 \\ -5 & 0.00 & 0.0 \\ -5 & -0.03 & 0.0 \\ -10 & -002 & 0.0 \\ -15 & 0.00 & 0.0 \\ -20 & +0.01 & 0.0 \\ -25 & +0.06 & -0.3 \\ -30 & +0.07 & -0.6 \\ -35 & +0.14 & -0.8 \\ -40 & +0.25 & -1.1 \\ -45 & - & -1.4 \\ -50 & - & -1.6 \\ -55 & - & -1.8 \\ -60 \mathrm{C} & - & -20\end{array}$

I wish also to mention the differential thermometer corrections described by Leyst in Wild's Repertorium für Meteorologie, Band. XIV., in which the temperature of the thread of mercury, when read, is different from that of the bulb, to which it is referred. Two cases are cited. 1. For a maximum thermometer, with separated thread (as, for instance. the Negretti and Zambra form), the thermometer is read at a different temperature from that at the time of maximum temperature, when the separation took place. For the ground-surface temperature at Nukuss, Leyst finds for a summer day a correction of $+0.73^{\circ} \mathrm{C}$., and that for the average of three summer months a correction of $+0.51^{\circ} \mathrm{C}$. must be applied to counteract this error. For the air temperawures the corrections ranged from $+0.10^{\circ} \mathrm{C}$. to $+0.20^{\circ} \mathrm{C}$. in the cases cited by Lesst. 2. The temperature of the thread of mercury and that of the bulb is not the same in the case of the wetbulb thermometer, when the difference in the temperatures of the wet- and dry-bulb thermometers does not vanish. Ordinarily, the thread is warmer than the mercury in the bulb. At a temperature of $30^{\circ} \mathrm{C}$., and a humidity of 50 per cent, there was a correction of $-0.30^{\circ} \mathrm{C}$., which means, for this case, an error of 0.5 millimeters in the absolute humidity, and of 2 per cent in the relative humidity.

\section{TO ANTHROPOLOGISTS.}

Department M of the World's Columbian Exposition includes all subdivisions of anthropology and history, although generally known as the "Department of Ethnology."

The anthropological portion of the department is subdivided into the following principal sections:

1. The Ethnographical Exhibition of Native American Peoples. The representatives of these peoples will be living in their native babitations on the grounds set apart for the purpose along the eastern shore of the Lagoon immediately north of the Anthropological Building.

2. 'The general Ethnological Exhibit in the building.

3. The general Archæological Exhibit in the building, and the casts of the several portions of the ancient ruins of Yucatan on the grounds in front of the main northern entrance to the Anthropological Building.

4. The general Exhibit of Ancient Religions, Games, and Folklore.

5. The Anthropological Laboratories on the northern gallery of the building. These laboratories will include special rooms devoted to physical anthropology, criminal anthropology, psychology, and neurology, and will be furnished with instruments and apparatus used in research, which will be carried on during the Exposition. The laboratories will also contain diagrams, charts, and tables illustrating various researches, particularly those relating to the physical characteristics of the native American peoples, and the comparison of the same with other races. There will also be diagrams illustrating the physical characteristics and the mental and physical development of school children in North America.

6. An Anthropological library covering all subdivisions of anthropology and allied sciences. For the purpose of making this library as perfect as possible and to enable students and educators to become acquainted with the mass of literature upon the subject, it is expected that authors, societies, museums, and publishers will contribute their books and papers relating to anthropology or any of its subdivisions, such as archæology, physical anthropology, psychology, neurology, etbnology, ethnography, primitive and ancient religions, myths, legends, folk-lore, languages, primitive art, primitive manufactures, etc., etc. The transactions, memoirs, journals, and proceedings of anthropological, ethnological, and archæological societies and museums. and the special papers ("reprints," "separata") of authors, are particularly desirable. There will be printed as soon as possible a full subject and autbor catalogue of the library. This catalogue will receive a wide circulation, and as it is intended that it shall be a reference catalogue for students and libraries, the publisher and price of each book and paper known to be for sale in any country will be given. The library will be carefully and properly arranged in book-cases in the room devoted to it, and will be under the special charge of assistants of the department, who will permit the volumes and papers to be referred to in the room and will give information as to their price and how to obtain them of agents, societies, and publishers. It will thus be seen that it is the intention to make known through this library the works of all writers upon anthropology so far as possible and that thousands of persons specially or cursorily interested in the subject will have an unrivalled opportunity of finding just the books and papers they wish to obtain.

The library will, after the close of the Exposition, be placed in the permanent Memorial Museum of Science, which is to be established in Chicago. It is therefore particularly requested that each contribution be sent to the Anthropological Library with a presentation slip stating that it is presented to the Columbus Memorial Museum. and the same will be duly acknowledged by the proper authorities when placed in the Museum Library after the close of the Exposition. In cases that may occur when contribubutions to the library are sent for use during the Exposition only, all such books or papers must be distinctly indicated by the words " to be returned" written orer the name and address of the owner or sender, and all so marked will be returned free of expense at the close of the Exposition. Every book and paper should be marked with the name and postoffice address of the sender. The books and papers should be sent by mail unless too bulky, in which case by express and should be addressed, World's Columbian Exposition, Department M, Anthropological Building, Chicago, Ill.

\section{GOLDSMITHS INSTITUTE ENGINEERING SOCIETY.}

\section{SIR FREDERICK BRAMWELL'S PRESIDENTIAL ADDRESS.}

AT the opening meeting of the session of the above society the president gave his inaugural address. Mr. Lincham occupiec the chair, and, after an introduction, Sir Frederick said :-

Mr. Lincham, ladies, and gentlemen: I am much flattered a being selected as president of the Goldsmiths Institute Engineer ing Society. I am an old member of the Goldsmiths Company having been connected with it some fifty years, and am a past prime-warden. I have to congratulate you upon the progress you have made, and am informed that, though your society has beer in existence but a few months, you now number orer 100 mem bers. You have two principal objects in view, one of which only 